\title{
Investigation of a typhoid fever epidemic in Moyale Sub-County, Kenya, 2014-2015
}

\author{
Dahabo Adi Galgallo ${ }^{1,2^{*}}$, Zeinab Gura Roka², Waqo G. Boru², Khalumi Abill ${ }^{1}$ and James Ransom ${ }^{2,3}$
}

\begin{abstract}
Aim: Typhoid fever is a vaccine-preventable bacterial disease that causes significant morbidity and mortality throughout Africa. This paper describes an upsurge of typhoid fever cases in Moyale Sub-County (MSC), Kenya, 2014-2015.

Methods: We conducted active hospital and health facility surveillance and laboratory and antimicrobial sensitivity testing for all patients presenting with headache, fever, stomach pains, diarrhea, or constipation at five MSC health facilities between December 2014 and January 2015. We also conducted direct observation of the residential areas of the suspected cases to assess potential environmental exposures and transmission mechanisms. Demographic, clinical, and laboratory data were entered into, and descriptive statistics were calculated with, MS Excel.

Results: A total of 317 patients were included in the study, with mean age $24 \pm 8.1$ years, and $51 \%$ female. Of the 317 suspect cases, 155 (49\%) were positive by Widal antigen reaction test. A total of 188 (59\%) specimens were subjected to culture and sensitivity testing, with 71 (38\%) culture positive and 54 (76\%), 43 (60\%), and 33 (46\%) sensitive to ceftriaxone, cefuroxime, and ciprofloxacin, respectively. Environmental assessments through direct observations showed that commercial and residential areas had limited (1) clean water sources, (2) latrines, and (3) hygiene stations for street food hawkers and their customers.

Conclusions: Typhoid fever is endemic in MSC and causes significant disease across age and sex groups. The local health department should develop policies to (1) assure community access to potable water and hygiene stations and (2) vaccinate specific occupations, such as food and drink handlers, against typhoid.
\end{abstract}

Keywords: Typhoid epidemic, Kenya, Sanitation, Laboratory

\section{Introduction}

Typhoid fever, caused by the bacterium Salmonella typhi (S. typhi), sickens millions of people each year and remains a significant public health problem in low-income countries [1]. Annual incidence in Africa ranges from 13 to 845 cases per 100,000 population, but its epidemiology in Kenya is poorly characterized [2]. In 2014, Moyale Sub-County (MSC), the northernmost point of Marsabit County, reported 3498 cases of typhoid-an annual incidence three times higher than the highest estimates in African countries [1]. MSC (population 130,000) shares a border with Ethiopia and is served by 90 health facilities comprised of 4 hospitals,

\footnotetext{
* Correspondence: adi.dahabo@yahoo.com

${ }^{1}$ Moyale Sub-County Hospital, Moyale, Marsabit County, Kenya

${ }^{2}$ Field Epidemiology and Laboratory Training Program, Ministry of Health,

Nairobi, Kenya

Full list of author information is available at the end of the article
}

17 health centers, 54 dispensaries, 13 private health facilities (nursing homes), and 2 functional clinical laboratories (Fig. 1). This report describes a hospitaland health facility-based epidemiological investigation of suspected typhoid cases at five health facilities in MSC, from December 2014 to January 2015.

\section{Methods \\ Descriptive epidemiology}

We conducted active hospital and facility surveillance for clinically diagnosed cases of typhoid fever by reviewing records from five health facilities in MSC of patients admitted between December 5, 2014, and January 5, 2015. Our case definition was any patient presenting with clinical signs and symptoms consistent with typhoid fever, including headache, fever, stomach pains, diarrhea, or chronic constipation. Laboratory procedures included rapid 


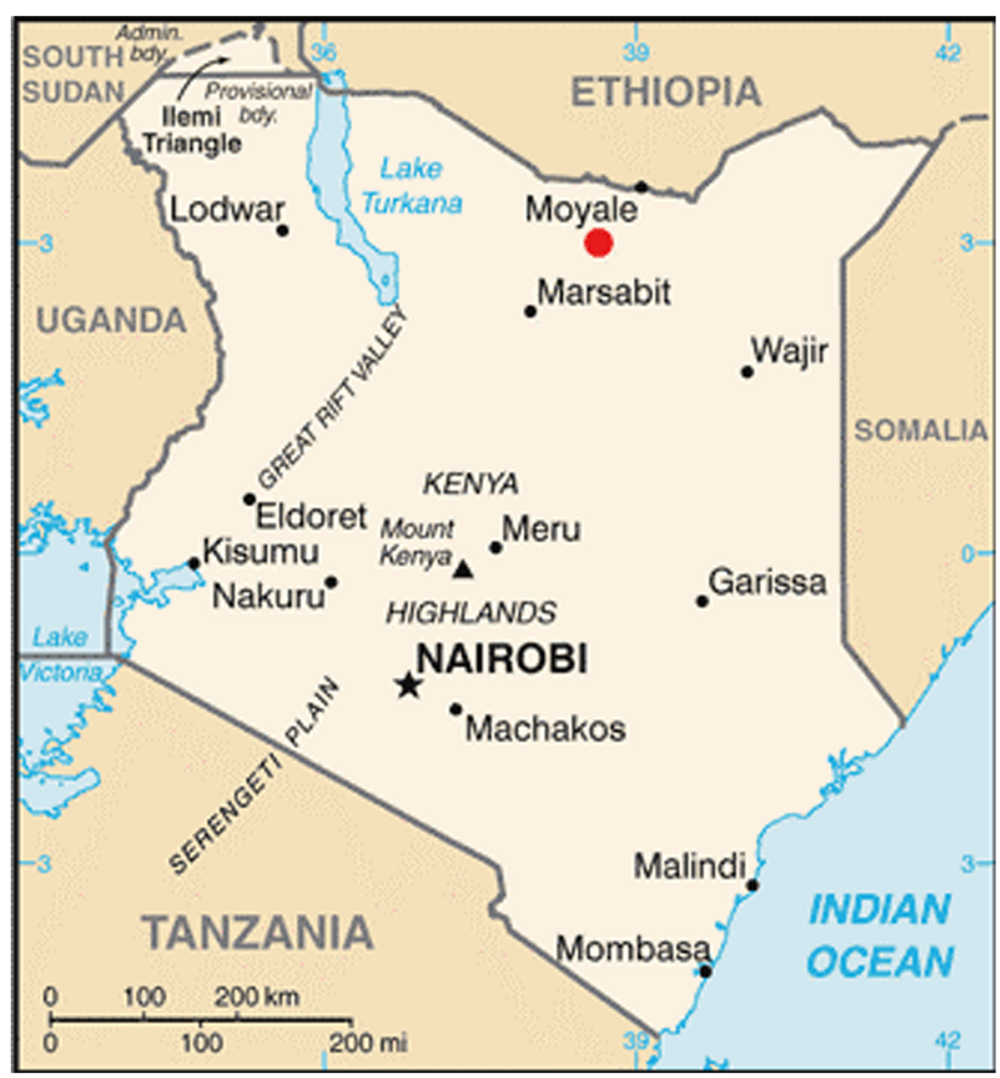

Fig. 1 Map of MSC

diagnostic tests (Widal), confirmatory culture from stool specimens, and antimicrobial sensitivity testing. Sociodemographic, clinical, and laboratory data were entered into, and descriptive statistics were calculated with, MS Excel.

\section{Environmental survey}

We conducted direct environmental observation and site visits to the most affected areas (based on reported residence of suspect cases) over a consecutive 3-day period. Each day was a 12-h continuous session in areas home to most cases to examine access to hygiene stations (toilets, water) and frequency of handwashing by food and drink vendors and their customers. Documentation included detailed observation notes and photographic evidence of the environment.

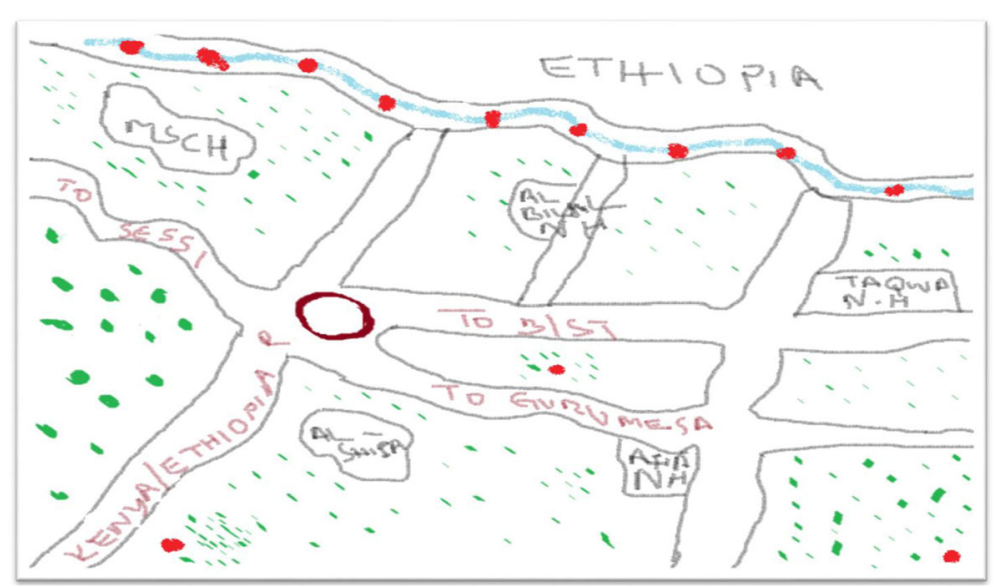

Fig. 2 Map of the five health facilities accessed as part of the typhoid epidemic investigation, Moyale Sub-County, Kenya, 2014-2015 


\section{Results}

\section{Descriptive epidemiology}

A total of 317 patients were identified between December 5,2014 , and January 5, 2015, with mean age of $24 \pm$ 8.1 years. Most [95 (30\%)] cases were from Taqwa Nursing Home. MSC Hospital and Al Shifa Clinic had $82(26 \%)$ and 73 (23\%) cases, respectively (Fig. 2).

\section{Laboratory}

Of the 317 patients, 155 (49\%) were positive via the Widal rapid diagnostic test, with $87(56 \%)<18$ years old. Of the 317 patients, 188 (59\%) submitted a stool specimen suitable for culture, of which 71 (38\%) showed growth. Antimicrobial testing on culture-positive samples showed sensitivity to ceftriaxone [54 (76\%)], ciprofloxacin [33 (46\%)], and cefuroxime [43 (60\%)], which is the drug of choice for treatment of typhoid in MSC (Table 1).

\section{Environmental assessment}

We observed multiple open-air food and drink markets in many of the areas where the cases reside (Fig. 3a, b). Within the city, there is a no-man's land between the Kenya and Ethiopia sides of MSC where animal and human waste are deposited very near a water source (Fig. 3c). Villages such as Manyatta and Butiye, which reported the fewest number of positive cases, depend on water from the main water supply or sometimes from harvested rain water. Analysis of the direct observation notes also showed that people in areas that reported most of the positive cases depend on water from shallow wells, which are likely contaminated with human waste (Fig. 3d).

During the $96 \mathrm{~h}$ of observation, 55\% (65/119) of vendors' and 69\% (37/54) of customers' fecal-hand contamination events were not followed within $15 \mathrm{~min}$ by handwashing. Potential transmission of fecal material to food, drink, or mouth occurred in $64 \%$ of cases within $1 \mathrm{~h}$ of hand contamination. When we measured the amount of water used at these sites, the mean water usage ( $6.5 \mathrm{l}$ ) was low compared to international disaster relief standards [3].

\section{Discussion}

A typhoid epidemic was detected in MSC due to an increase in the numbers of Widal tests performed at the MSC Hospital laboratory in 2014. This epidemic, which may be part of an overall increase in prolonged, severe, and widespread typhoid outbreaks in both rural and urban populations in Africa, seemed to be predicated on limited access to and use of safe water and sanitation [4]. One possible explanation for the low use of water and poor hand hygiene practices, especially in areas with many commercial food and drink vendors, is the lack of
Table 1 Patient demographic characteristics and positive typhoid laboratory results, Moyale Sub-County, Kenya, 2014-2015

\begin{tabular}{|c|c|}
\hline Variable & $N(\%)$ \\
\hline \multicolumn{2}{|l|}{$\operatorname{Sex}(n=157)$} \\
\hline Male & $77(49)$ \\
\hline Female & $80(51)$ \\
\hline \multicolumn{2}{|l|}{ Age group (years) $(n=155)$} \\
\hline$<18$ & $87(56)$ \\
\hline$>18$ & $68(44)$ \\
\hline \multicolumn{2}{|l|}{ Facility $(n=157)$} \\
\hline Taqwa Nursing Home & $47(30)$ \\
\hline Moyale Sub-County Hospital & $40(26)$ \\
\hline Al Shifa Clinic & $36(23)$ \\
\hline Afya Nursing Home & $17(11)$ \\
\hline Al Bilal Nursing Home & $16(10)$ \\
\hline \multicolumn{2}{|l|}{ Residence $(n=155)$} \\
\hline Township & $37(24)$ \\
\hline Biashara Street & $37(24)$ \\
\hline Sessi & $37(24)$ \\
\hline Butiye & $22(14)$ \\
\hline Manyatta & $17(11)$ \\
\hline Gurumesa & $5(3)$ \\
\hline \multicolumn{2}{|l|}{ Laboratory } \\
\hline Widal $(n=317)$ & $155(49)$ \\
\hline Culture $(n=188)$ & $71(38)$ \\
\hline \multicolumn{2}{|c|}{ Antimicrobial sensitivity testing $(n=71)$} \\
\hline Ceftriaxone & $54(76)$ \\
\hline Cefuroxime & $43(60)$ \\
\hline Ciprofloxacin & $33(46)$ \\
\hline Ofloxacin & $27(38)$ \\
\hline Nitrofurantoin & $25(35)$ \\
\hline Chlorophenicol & $23(32)$ \\
\hline Gentamicin & $19(26)$ \\
\hline Amoxicillin & $11(15)$ \\
\hline
\end{tabular}

Any record that did not contain the specific part of the case's

sociodemographic information was excluded from the analysis; therefore, denominators differ from one variable to the next

regular access to chlorination products [5]. In lowincome countries like Kenya, typhoid infection is usually acquired by consumption of food or water contaminated with human excreta that contains S. typhi [1].

Our results via direct observation of the cases' environments highlight the need for more effective interventions to improve knowledge of typhoid fever transmission and prevention and increase uptake of preventive behaviors such as handwashing [6, 7]. Areas experiencing inaccessibility to clean and safe water like Sessi, Township, and Biashara Street had 


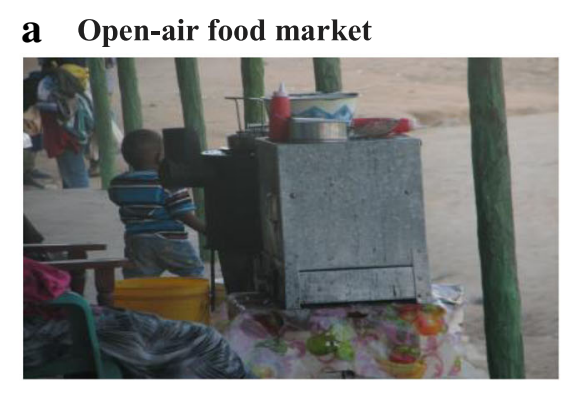

b Open-air milk and drink market

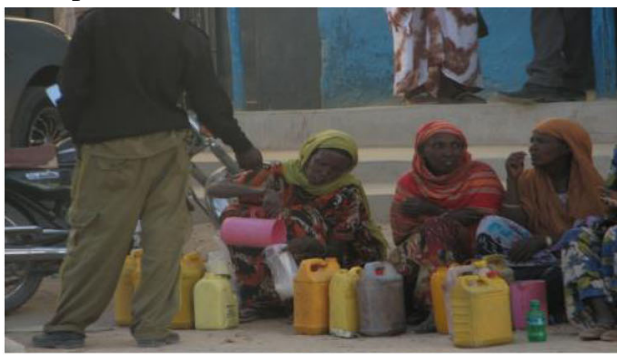

c Neutral zone, Kenya-Ethiopia border

d Accessing water at shallow well
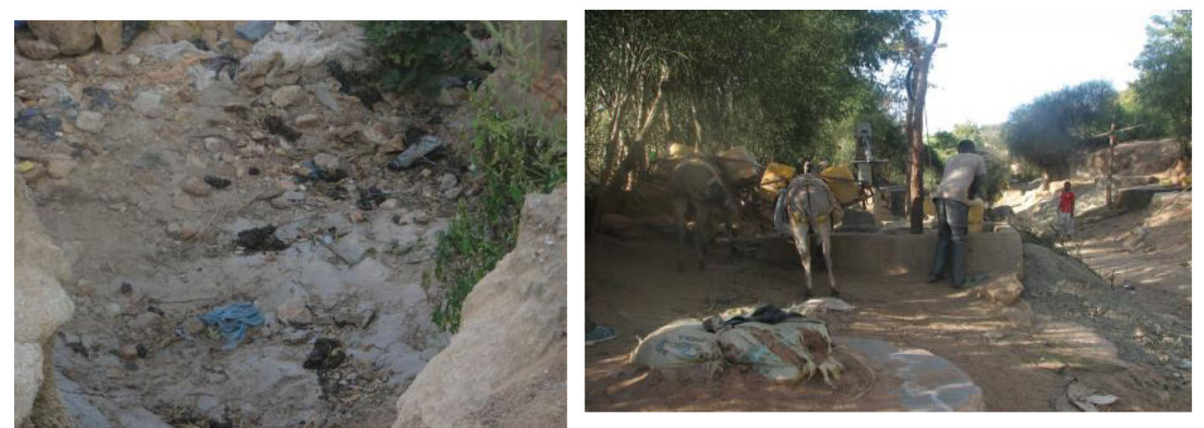

Fig. 3 a-d Potential sources of spread documented during direct observation/environmental assessments, typhoid epidemic investigation, Moyale Sub-County, Kenya, 2014-2015

the most cases (111 [71\%]), whereas areas with access to clean water like Butiye, Manyatta, and Gurumesa had the fewest cases (44 [28\%]). Areas where food hawking was rampant, such as in Township and Biashara Street, had more cases of people who were $<18$ years of age, possibly due to more frequent visits to the food and drink vendors.

In our study, the antimicrobial sensitivity results and the overall culture results are suspect because of rampant self-medication with antibiotics that can be purchased at pharmacies throughout MSC. It is probable, from the histories provided by the patients, that they had antibiotic treatment prior to coming to hospital, hence complicating our ability to interpret culture results [8].

Despite better surveillance and understanding of the epidemiology of typhoid fever, public health seems to be losing the battle against typhoid fever in most African countries [9]. Traditional "hygiene" recommendations did not prevent this epidemic, as there was no mechanism for the communities to remediate the water that was available to them nor to install proper latrines near their homes or near the market areas. Because necessary improvements to water and sanitation are likely to take decades to achieve, we think that targeted and appropriate vaccination campaigns or availability of typhoid vaccines at health facilities could potentially reduce morbidity and mortality [10]. Recommendations should also focus on targeting water treatment packs to the areas that have the bulk of cases, which would reduce risk of specific practices rather than discuss elimination, which is not practical in most affected areas.

\section{Abbreviations}

MSC: Moyale Sub-County; S. typhi: Salmonella typhi

\section{Acknowledgements}

We thank the clinical and laboratory staff at the five health facilities in Moyale Sub-County and the faculty and staff at the Kenya Field Epidemiology and Laboratory Training Program in Nairobi.

\section{Authors' contributions}

DAG, ZGR, KA, and WGB designed the study. KA and DAG conducted all laboratory procedures. JR and DAG organized and analyzed all data. DAG and KA conducted the environmental assessment observations and created the community map. JR conducted the final data analysis and checks. All authors read and approved the final manuscript.

\section{Ethics approval and consent to participate}

Ethical approval was granted by the head of Moyale Sub-County Hospital and Department of Public Health, Moyale Sub-County, Kenya.

\section{Consent for publication}

All authors consent to the publication of this manuscript.

Competing interests

The authors declare that they have no competing interests. 


\section{Publisher's Note}

Springer Nature remains neutral with regard to jurisdictional claims in published maps and institutional affiliations.

\section{Author details}

${ }^{1}$ Moyale Sub-County Hospital, Moyale, Marsabit County, Kenya. ${ }^{2}$ Field Epidemiology and Laboratory Training Program, Ministry of Health, Nairobi, Kenya. ${ }^{3}$ Piret Partners Consulting, Washington DC, USA

Received: 17 March 2017 Accepted: 30 April 2018

Published online: 15 May 2018

\section{References}

1. Mogasale V, Maskery B, Ochiai RL, Lee JS, Mogasale W, Ramani E, Kim YE, Park JK, Wierzba TF. Burden of typhoid fever in low-income and middleincome countries: a systematic, literature-based update with risk-factor adjustment. Lancet Glob Health. 2014;2(10):e570-80.

2. Wirth T. Massive lineage replacements and cryptic outbreaks of Salmonella typhi in eastern and southern Africa. Nat Genet. 2015;47(6):565.

3. Obani P, Gupta J. Human security and access to water, sanitation, and hygiene: exploring the drivers and nexus, Handbook on water security; 2016. p. 201.

4. Bennett SD, Lowther SA, Chingoli F, Chilima B, Kabuluzi S, Ayers TL, Warne $T A$, Mintz E. Assessment of water, sanitation and hygiene interventions in response to an outbreak of typhoid fever in Neno District. Malawi PloS one. 2018;13(2):e0193348.

5. Branz A, Levine M, Lehmann L, Bastable A, Ali SI, Kadir K, Yates T, Bloom D, Lantagne D. Chlorination of drinking water in emergencies: a review of knowledge to develop recommendations for implementation and research needed. Waterlines. 2017;36(1):4-39.

6. Alba S, Bakker Ml, Hatta M, Scheelbeek PF, Dwiyanti R, Usman R, Sultan AR, Sabir M, Tandirogang N, Amir M, Yasir Y. Risk factors of typhoid infection in the Indonesian archipelago. PLoS One. 2016;11(6):e0155286.

7. Ali E, Van Den Bergh R, D'hondt R, Kuma-Kuma D, De Weggheleire A, Baudot Y, Lambert V, Hunter P, Zachariah R, Maes P. Localised transmission hotspots of a typhoid fever outbreak in the Democratic Republic of Congo. Pan Afr Med J. 2017;28(1):1-9.

8. Kajeguka DC, Moses E. Self-medication practices and predictors for selfmedication with antibiotics and antimalarials among community in Mbeya City, Tanzania. Tanzania J Health Res. 2017;19(4):1-10

9. Antillón M, Warren JL, Crawford FW, Weinberger DM, Kürüm E, Pak GD, Marks F, Pitzer VE. The burden of typhoid fever in low-and middleincome countries: a meta-regression approach. PLoS Negl Trop Dis. 2017;11(2):e0005376

10. Walldorf JA, Date KA, Sreenivasan N, Harris JB, Hyde TB. Lessons learned from emergency response vaccination efforts for cholera, typhoid, yellow fever, and Ebola. Emerg Infect Dis. 2017;23(Suppl 1):S210.

Ready to submit your research? Choose BMC and benefit from:

- fast, convenient online submission

- thorough peer review by experienced researchers in your field

- rapid publication on acceptance

- support for research data, including large and complex data types

- gold Open Access which fosters wider collaboration and increased citations

- maximum visibility for your research: over $100 \mathrm{M}$ website views per year

At BMC, research is always in progress.

Learn more biomedcentral.com/submissions 